\title{
Patient satisfaction and occupational health of workers in hospital care setting: Associations and reciprocity
}

\author{
Marco Ferrara, Daniela Converso*, Sara Viotti \\ Department of Psychology, University of Turin, Turin, Italy; \\ *Corresponding Author: daniela.converso@unito.it
}

Received 29 July 2013; revised 29 August 2013; accepted 15 September 2013

Copyright (C) 2013 Marco Ferrara et al. This is an open access article distributed under the Creative Commons Attribution License, which permits unrestricted use, distribution, and reproduction in any medium, provided the original work is properly cited.

\section{ABSTRACT}

Research studies conducted in the healthcare sector usually examine patients' and workers' wellbeing as separate entities; however, recent studies have revealed significant correlations between, for example, patient satisfaction, workers stress and burnout. The present study examines the relationships between patient perceived quality of care (in terms of satisfaction with regard to accessibility, organizational efficiency and humaneness of care), and workers' perceived quality of organizational life (in term of organizational support and availability of resource and reward), quality of relationship in the work-unit (superior and coworkers), quality of relationship with patients (disproportionate client expectations and customer verbal aggression) and individual health (emotional exhaustion and depersonalization, job satisfaction). 147 workers and 132 patients from seven hospital wards in northern Italy constitute the data base for the study. Analyses showed that accessibility and humaneness of care were negatively associated with disproportionate patient expectations, patient verbal aggression, emotional exhaustion and positively associated with availability of material recourses. Moreover, accessibility was also positively associated with the organizational support while organizational efficiency with support from colleagues. Globally, the results of the present study confirm that staff wellbeing is an essential aspect in relation to the patient perception of the quality of care and supporting the assumption that healthy organizations improve the wellbeing of their workers, their organizational performance and the quality of their service at the same time.

Keywords: Patients Satisfaction; Quality of Care; Occupational Wellbeing; Job Burnout; Work-Related Stress; Health Care Setting

\section{INTRODUCTION}

Alongside other clinical, economic and health aspects, patient satisfaction is increasingly considered to be an essential dimension when assessing quality of care [1]. Indeed, the current perspective centered on the patient no longer sees the latter as a passive recipient of necessary procedures, but rather as an actor taking an active role in the process of care and prevention [2].

As regards the definition, patient satisfaction is a weak concept and finds little agreement among researchers, which is due, above all, to the fact that the development of measuring instruments has rarely been preceded by a reflection on the conceptual and theoretical aspects of patient satisfaction itself [3]. The most important theories on patient satisfaction were elaborated in the 1980s and the most recent conceptual contributions to the debate referring widely to these theories [4]. One aspect common to the majority of these theories is the multidimensionality of construct: "a health care recipient's reaction to salient aspects of the context, process, and result of their service experience" [5]. For example, Ware et al. [6], on the basis of an analysis of questionnaire content as reported in the literature, identify eight principal components which define patient satisfaction: interpersonal approaches (how operators interact with patients); technical quality of care (operator skills and adherence to high standards of diagnosis and care); accessibility (factors involved in arranging to receive medical care); finance (economic factors in the medical service); effectiveness (which concerns the results of the service provided); continuity 
of care (consistency of operator or place of care); physical environment (characteristics of the setting in which the care is provided); availability (of resources for medical care).

There are also theories which include patient expectations as a key concept in satisfaction and define this construct as the degree of congruence between expectations and their fulfillment. Similarly, Fox and Storm [7] postulated that patients have their own personal orientation concerning care, and that if care is congruent with this orientation, the outcome is one's satisfaction, and if not, the patient is unsatisfied.

Other theories have emphasized the role of the interpersonal process of care. For example, Donebedian [8] asserted that patient satisfaction (or dissatisfaction) is the result of the evaluation, by the patient, of the care in all its facets, but above all in relation to interpersonal components. This appears to be in agreement with Bowers, Swan, and Koehler [9], who suggest that the assessment project which underlies patient satisfaction is connected to communication, responsiveness and reliability rather than to technical aspects, which are less likely to be evaluated by recipients of care. Hall and Dornan [10], in their meta-analytic review, highlighted how most definitions of patient satisfaction concerned overall quality, humaneness of care, competence and effectiveness, while costs, bureaucracy and psychological problems have received less attention from researchers.

In the literature, much attention has been dedicated to identifying which factors correlate with patient satisfaction, but no consensus has been reached in this regard. Part of the complexity of patient satisfaction as a phenomenon lies in the fact that it is influenced by numerous aspects including cultural, demographic, cognitive and affective ones. The earliest studies from the 1980s focused the attention on the variables socio-demographic factors (so called "background variables") [11-14], but the contradictory results convinced many researchers to conclude that socio-demographic characteristics are the least significant predictors of patient satisfaction [10].

\section{Patient Satisfaction and the Occupational Health of Workers}

Over the last decade, Occupational Health Psychology [15] has become increasingly interested in the study of patient satisfaction, conceiving of it, above all, as related to the wellbeing of workers. In this regard, it is necessary to bear in mind the theoretical framework of the so-called "Healthy Organizations" [16], which "develop systematic, planned, and proactive efforts in improving the employee and the financial health" and, through good practices, aim to promote at the same time: 1) a healthy working environment; [17]; 2) healthy workers and 3) organizational outcomes which express health (patient satisfaction).

Most of the studies which have examined the health of workers in relation to patient satisfaction have mainly focused on burnout, highlighting a close and negative correlation between patient satisfaction and dimensions of emotional exhaustion, while depersonalization and professional fulfillment show less compelling connections [18-21].

There is, in addition, a very small number of studies which have examined other variables both of an individual and an organizational type in relation to user satisfaction. For example, Leiter et al. [18] have found a significant association with the meaningfulness of work and Weng and colleagues [22] with staff emotional intelligence. Intention to leave the job has shown strong associations with patient dissatisfaction in two research studies $[18,20]$.

One interesting aspect which has received little attention in the literature is the association between quality of the service perceived by patients and quality of the working environment perceived by operators. In Vahey et al. [20] study, for example, when workers perceived positive staff climate, support from supervisors and positive relations with patients, patient satisfaction increased as well. Moreover, Teng and colleagues [23] reported that time pressures on nurses may influence the perception of patients with regard to the quality of service in terms of reliability, responsiveness and safety.

\section{AIM OF THE STUDY}

The present study aims at investigating the relationships between patient perceived quality of care (in terms of satisfaction with regard to accessibility, organizational efficiency and humaneness of care), and workers' perceived quality of organizational life (in term of organizational support and availability of resource and reward), quality of relationship in the work-unit (superior and coworkers) quality of relationship with patients (disproportionate client expectations and customer verbal aggression), and individual health (emotional exhaustion and depersonalization, job satisfaction).

\section{METHOD}

The project was carried out under an agreement signed in 2010 between the Department of Psychology of the University of Turin and one of the largest hospitals in the city. The purpose was to develop practices devised to enhance the quality of life of patients and operators. The research, provided for the administration, at two distinct moments, of questionnaires both for operators and patients. The project, made available to all the twenty-five departments of the hospital, included finally only those units - seven — where more than the $50 \%$ of workers and 
patients completed the two questionnaire: renal unit, general medicine, cardiology, orthopaedics, elderly services, nephrology, emergency medicine.

\subsection{Staff Survey}

147 operators completed a questionnaire independently during working hours. The group comprises 91 professional nurses 32 doctors and 24 nurses aides distributed in differing proportions by department (renal unit: $19.7 \%$, medicine: $15 \%$, cardiology: $11.6 \%$, orthopaedics: $10.9 \%$, elderly services: $8.8 \%$; nephrology $11.6 \%$, emergency medicine: $22.4 \%$ ).

Most of the workers were women $(\mathrm{F}=119 ; 81 \% ; \mathrm{M}=$ $17 ; 18.4 \%)$ and mean age was 40.7 years $(\mathrm{sd}=9.4$, min. $=22$ years, max. $=59$ years $)$. Most regularly worked night shifts $(90 ; 61.2 \%)$, had a permanent contract $(\mathrm{n}=$ $124 ; 84.4 \%)$ and a full-time contract $(\mathrm{n}=134 ; 91.2 \%)$. The average working week was of 36.88 hours $(\mathrm{sd}=6.9)$ and, lastly, the mean time period spent in the department was 9.8 years $(\mathrm{sd}=7.3)$, while the number of years in the healthcare sector was $15.7(\mathrm{sd}=9.8)$.

\subsection{Staff Measures}

Doctors and nurses completed a questionnaire including items on socio-demographic characteristics and scales measuring the quality of organizational life (organizational support and availability of resource and reward), quality of the relationship in the unit (superior and coworkers) and quality of relationship with patients (disproportionate client expectations and customer verbal aggression, emotional exhaustion and depersonalization).

Quality of organizational life was investigated by means of four sub-scales. Organizational support: scale included in a recent revision of Job Content Questionnaire (JCQ [24,25]) containing four items evaluating the degree to which organization policies consider the well-being, values and intentions of the workers (e.g. item "My organization really cares about my well-being"). Availability of resources: this subscale has been constructed specifically for the present study and consists of three items studying the presence of instrumental, technological and human resources to accomplish the job (e.g. item "I have the facilities, the methods and the instruments I need on a daily basis at work").

For quality of relationship in the work-unit were employed two scales of JCQ [24] that investigate respectively vertical (six items, e.g., item "My supervisor is helpful in getting the job done") and horizontal social support (from peers and colleagues; five items "People I work with are competent in doing their jobs").

In order to measure quality of the relationship with patients two subscales adapted from the questionnaire "Customer-Related Social Stressors" by Dormann and
Zapf (CSS, [26]) are here included. The first called "disproportionate client expectations" contains eight items examining behaviours of patients perceived by workers, such as requesting special attention, or having things done for them which they could do by themselves (e.g., item "Our patients' demands are often exorbitant"). The second "customer verbal aggression" contains four items and regards the behaviours of complaint or argumentativeness of the patients or their relatives (e.g., item "Patients get angry at us even over minnor matters").

Workers health was measured by means of job burnout and job satisfaction.

Job burnout: Two subscale from the Italian version of Maslach Burnout Inventory (MBI [27,28]) were employed: the first is the emotional exhaustion scale (nine items, e.g., item: "I feel emotionally drained from my work") examining the presence of feelings of tiredness and of being drained in the operator as a consequence of the work. The second scale is depersonalization which is intended to detect the presence of negative and cynical attitudes vis-à-vis the patients (five items; e.g. item "I feel I treat some patients as if they were impersonal objects").

Job satisfaction: was measured by means of a scales coming from the Copenhagen Psychosocial Questionnaire (COPSOQ, [29]) that contains seven items aimed at capturing satisfaction with several aspect of the job such as reward, career prospects and skill discretion (e.g. items: "how satisfied are you with the way your abilities are used?").

Responses on all sub-scales were given on a four-point scale with a range between 1 ("strongly disagree") and 4 ("strongly agree") save for job burnout (ranging from $0=$ "never" to $6=$ "every day").

The reliability of all the subscales on occupational quality of life is satisfactory as all values of Cronbach's alpha are greater than 0.70 (see Table 1).

\subsection{Patient Survey}

Patients participated in the client survey by means of a structured interview. The research team entered the wards in the hours of inpatient stay, or of outpatient service, on days previously arranged with department managers. Participation was on a voluntary basis and did not include patients who were sedated, in significant pain or incapable of understanding, be it temporarily or permanently.

Of the 132 participants, 64 were men (48.5\%) and 65 women $(49.5 \%)$, as such the two gender categories were evenly distributed. The mean age of the participants was of 65.97 years with a range of $24-101$.

With regard to the departments, the patients were thus distributed: renal unit $(28.8 \%)$, general medicine (10.6\%), cardiology $(13.6 \%)$, orthopaedics $(14.4 \%)$, elderly ser- 
Table 1. Cronbach's alpha and descriptive statistics of subscales.

\begin{tabular}{cccc}
\hline & $\alpha$ & $\mathrm{M}(\mathrm{sd})$ & Min-max \\
\hline Staff survey & & & \\
Availability of resources & 0.89 & $5.7(1.1)$ & $3-12$ \\
Organizational support & 0.87 & $10.15(2.3)$ & $4-15$ \\
Supervisor support & 0.79 & $17.3(3.9)$ & $6-24$ \\
Colleagues support & 0.82 & $19.1(3.1)$ & $9-24$ \\
Disproportionate customer expectations & 0.74 & $20.17(5.0)$ & $9-32$ \\
Customer verbal aggression & 0.81 & $8.3(3.4)$ & $4-16$ \\
Emotional exhaustion & 0.92 & $18.6(12.5)$ & $0-54$ \\
Depersonalization & 0.76 & $5.67(5.5)$ & $0-24$ \\
Job satisfaction & 0.74 & $18.81(3.5)$ & $7-28$ \\
Patient survey & & & \\
Accessibility & 0.73 & $10.46(1.6)$ & $5-12$ \\
Humaneness of care & 0.84 & $13.60(2.4)$ & $5-16$ \\
Organizational efficiency & 0.90 & $21.46(3.2)$ & $8-24$ \\
\hline
\end{tabular}

vices $(10.6 \%)$, nephrology (11.4\%), emergency medicine (10.6\%).

In terms of state of health, most were chronic patients $(80 ; 60.6 \%)$ and $34.1 \%$ had an acute condition. 38 , the $28.8 \%$, were outpatients, 93 the $70.5 \%$, were inpatients. Lastly, most of the participants declared that they had received documentation explaining the treatment or the diagnosis (yes: $80 ; 60.6 \%$; no: $52 ; 39.4 \%$ ).

\subsection{Patient Measures}

The questionnaire addressed to the patients, represents an adaptation of the "Questionnaire on the assessment of perceived quality in integrated home care" [30]. Patient satisfaction is examined by means of a single scale composed of fifteen items with four possible responses ( $1=$ very badly; $4=$ very well). This instrument has a socio-demographic section and evaluates patient satisfaction indirectly by asking for evaluations of the quality of care received, understood as skills and concern for the patient displayed by doctors, nurses and other members of staff, or else effectiveness of the information received. The items in the questionnaire derive from three sub-dimensions which cast light on the different facets of the phenomenon:

Accessibility: five items which investigate the ease of access in cultural and physical terms as well as the ability of the staff to communicate with patients and family members (e.g., item "how do you evaluate the clarity and intelligibility of the language used by the medical staff?");

Organizational efficiency: this dimension examines the patient's perception of the functionality and organization of the service; four items ask the patient to express their perception regarding the punctuality of appointments, care needs, skills of the staff and presence over time of the same staff members (e.g., item: "how do you evaluate the punctuality of the appointments, the timeliness of check-ups and treatment?");

Humaneness of care: this regards the acceptance of the needs for humanization and of personalization of care; seven items examine patients' perceptions of encouragement and support from the operators, relations between workers, willingness displayed to meet the needs of the patient, politeness, and confidence inspired by the staff (e.g., item: "how do you evaluate the willingness of the nurses to meet patient needs?").

The reliability of all the subscales on the occupational quality of life is satisfactory since all values of Cronbach's alpha are greater than 0.70 (see Table 1).

\subsection{Data Analyses}

All the analyses were performed using PASW Statistics 20. The associations between patient satisfaction and workers' perception of their work quality life were made with Spearman's rank correlation coefficient using unit means (rank order correlation).

\section{RESULTS}

Table 2 shows the associations between patient satisfaction and the perception of operators about their own health and working conditions.

Dimensions which describe the quality of organizational life, both accessibility $(\rho=0.79 ; \mathrm{p}=0.03)$ and humaneness of care $(\rho=0.82 ; \mathrm{p}=0.02)$ displays a positive association with material resources. Moreover, accessibility show also a positive significant association with organizational support $(\rho=0.79 ; \mathrm{p}=0.03)$.

Turning our attention to those dimensions which describe quality of social relation within units no significant relationships were found between patient satisfaction and the support of superiors reported by the operators. Organizational efficiency $(\rho=0.79 ; \mathrm{p}=0.03)$ displays a positive association with support of colleagues.

Concerning dimensions describing quality of relationship with patients, "aggressive behaviours by patients" and "disproportionate patient expectations" display a negative association both with the dimension of accessibility $\left(\rho_{\text {aggressive behaviours }}=-0.86 ; \mathrm{p}=0.01 ; \rho_{\text {disproportionate }}\right.$ expectations $=-0.76 ; p=0.05)$ and with the one of humaneness of care $\left(\rho_{\text {aggressive behaviours }}=-0.86 ; \mathrm{p}=0.01\right.$; $\left.\rho_{\text {disproportionate expectations }}=-0.86 ; \mathrm{p}=0.01\right)$. No association were found in the organizational efficiency dimension.

Finally, emotional exhaustion shows a significant negative association with the dimensions of accessibility to the service $(\rho=-0.96 ; p=0.00)$ and humaneness of care $(\rho=-0.86 ; \mathrm{p}=0.14)$. Conversely, no significant 
Table 2. Correlation Coefficients (Spearman $\rho$ ) between Patient Satisfaction subscales and staff working quality of life indicators.

\begin{tabular}{cccc}
\hline & Accessibility & Humaneness of care & Organizational efficiency \\
\hline Material resources & $0.79^{*}$ & $0.82^{*}$ & 0.64 \\
Organizational support & $0.79^{*}$ & 0.71 & 0.71 \\
Supervisor support & -0.07 & 0.07 & 0.46 \\
Colleagues support & 0.64 & 0.75 & $0.79^{*}$ \\
Patient verbal aggression & $-0.86^{*}$ & $-0.86^{*}$ & -0.61 \\
Disproportionate patient expectations & $-0.76^{*}$ & $-0.86^{*}$ & -0.52 \\
Emotional exhaustion & $-0.96^{* *}$ & $-0.86^{*}$ & -0.68 \\
Depersonalization & -0.39 & -0.46 & -0.21 \\
Job satisfaction & 0.43 & 0.42 & 0.07 \\
\hline
\end{tabular}

${ }^{*} \mathrm{p}<0.05 ;{ }^{* *} \mathrm{p}<0.01$.

relationship was found between patient satisfaction and job satisfaction.

\section{DISCUSSION}

The aim of this research was to study the association between patients' satisfaction with care and quality of life at work perceived by care staff.

Globally, the results confirm that staff wellbeing is a central aspect in relation to the quality of service and would support the assumption that healthy organizations improve the wellbeing of their workers, their organizational performance and the quality of their product/ service, at one and the same time [16]; this is all the more true in care settings where the quality of work can have additional effects on the wellbeing of the users and on their satisfaction [31]. This study reinforces the need for contrasting stress and fostering wellbeing of health care workers to promote quality in care and patient satisfaction at the same time [32].

Furthermore, several considerations on the significant associations found should be provided. First of all, it is possible to observe that the strongest association concerns relational/affective aspects, and less from an organization technical point of view. Accessibility and humanness of care - concern affective aspects such as communication, politeness and attention to the needs of the patient-display significant associations with most of all dimensions that concern the relationship with patients (disproportionate expectations of the users, customer verbal aggression but also emotional exhaustion).

These results are in agreement with those obtained by previous studies on reciprocity between recipients and providers of care [33]. They suggest that patients, in assessing the quality of service, tend to take into consideration above all relational aspects, while "taking for granted" the appropriateness of technical ones [18]. For this reason, when providers of care are emotionally stressed and unable to meet patients' expectations, pa- tient satisfaction tends to decrease.

Moreover, support coming from organization seems to have a role in influencing accessibility since that both organizational support and availability of resources were found positively associated with the dimension of accessibility. In particular, the "material resources" subscale, as explained above, examines the perception of the staff about the availability of human and technical resources necessary to provide fitting service and care. It is possible to hypothesize that in consequence of staff shortages, and also of limitations on the technology employed in the processes of care, due to the reduction in resources seen in public health in the last few years, hospital staff may only dedicate a limited time to their relations with the patients, who, in turn, report lower levels of satisfaction. These results are consistent with the findings of Teng et al. [23] which had shown a correlation between time pressures and patient satisfaction.

Lastly, for organizational efficiency, only the significant correspondence with social support was found. This finding suggests that a good relationship within the unit positively affects technical aspects such as the appropriateness of staff skills and the punctuality and timeliness of the appointments and of the check-ups. Also Vahey and colleagues [20] found a similar result. Future studies should investigate more thoroughly the relationship between patient satisfaction and social support.

The present study has several limitations. One of these concerns the small size of the sample in a single hospital, which limits the generalizability of the results and does not allow more extensive analyses (e.g., multilevel analysis) to be performed.

Although, as has been pointed out several times, the results produced are consistent with the hypothesis that wellbeing at work can influence patient satisfaction, the present study is a cross-sectional one and, as such, does not make it possible to demonstrate either the directionality or the causality of the relations observed between the wellbeing of the workers and patient satisfaction. 
Future studies might wish to consider an experimental design of a longitudinal type to obviate this limitation.

\section{ACKNOWLEDGEMENTS}

We would like to thanks San Giovanni Bosco Hospital administration for giving us the opportunity to further the present research.

Special thanks to Mrs. Ivana Finiguerra for her support during data collection.

\section{REFERENCES}

[1] Heidegger, T., Saal, D. and Nueblin, M. (2006) Patient satisfaction with anesthesia care: What is patient satisfaction, how should it be measured, and what is the evidence for assuring high patient satisfaction. Best Practice and Research Clinical Anesthesiology, 20, 331-346. http://dx.doi.org/10.1016/j.bpa.2005.10.010

[2] Mead, N. and Bower, P. (2002) Patient-centred consultations and outcomes in primary care: A review of the literature. Patient Education and Counseling, 48, 51-61. http://dx.doi.org/10.1016/S0738-3991(02)00099-X

[3] Arnetz, J.E. and Arnetz, B.B. (1996) The development and application of a patient satisfaction measurement system for hospital-wide quality improvement. International Journal for Quality in Health Care, 8, 555-566. http://dx.doi.org/10.1093/intqhe/8.6.555

[4] Gill, L. and White, L. (2009) A critical review of patient satisfaction. Leadership in Health Services, 22, 8-19. http://dx.doi.org/10.1108/17511870910927994

[5] Pascoe, G.C. (1983) Patient satisfaction in primary health care: A literature review and analysis. Education and Program Planning, 48, 12-40.

[6] Ware, J.E., Snyder, M.K., Wright, W.R. and Davies, A.R. (1983) Defining and measuring patient satisfaction with medical care. Education and Program Planning, 6, 669682.

[7] Fox, J.G. and Storm, D.M. (1981) A different approach to sociodemographic predictors of satisfaction with health care. Social Science \& Medicine, Part A: Medical Sociology, 15, 557-564. http://dx.doi.org/10.1016/0271-7123(8)90079-1

[8] Donabedian, A. (1980) The definition of quality and approaches to its assessment Exploration in quality assessment and monitoring, Volume 1. Health Administration Press, Ann Arbor.

[9] Bowers, M.R., Swan, J.E. and Koehler, W.F. (1994) What attribute determine quality and satisfaction with health care delivery? Health Care Management Review, 19, 4955. http://dx.doi.org/10.1097/00004010-199401940-00006

[10] Hall, J.A. and Dorman, M.C. (1990) Patient sociodemografic characteristics as predictors of satisfaction with medical care. A Meta-Analysis. Social Science and Medicine, 30, 811-818. http://dx.doi.org/10.1016/0277-9536(90)90205-7

[11] Cohen, G. (1996) Age and health status in a patient satisfaction survey. Social Science \& Medicine, 42, 1085-1109. http://dx.doi.org/10.1016/0277-9536(95)00315-0
[12] Capuzzo, M., Gili, G., Paparella, L., Gritti, G., Gambi, D., Bianconi, M., Giunta, F., Buccoliero, C. and Alvisi, R. (2007) Factors predictive of patient satisfaction with anesthesia. Anesthesia \& Analgesia, 105, 435-442. http://dx.doi.org/10.1213/01.ane.0000270208.99982.88

[13] Ndambuki, J. (2013) The level of patients' satisfaction and perception on quality of nursing services in the Renal unit, Kenyatta National Hospital Nairobi, Kenya. Open Journal of Nursing, 3, 186-194. http://dx.doi.org/10.4236/ojn.2013.32025

[14] Rahmqvist, M. and Bara, A. (2010) Patient characteristics and quality dimensions related to patient satisfaction. International Journal for Quality in Health Care, 22, 86-92. http://dx.doi.org/10.1093/intqhe/mzq009

[15] Schaufeli, W.B. (2004) The future of occupational health psychology. Applied Psychology: An International Review, 53, 502-517. http://dx.doi.org/10.1111/j.1464-0597.2004.00184.x

[16] Salanova, M., Llorens, S., Cifre, E. and Martínez, I.M. (2012) We need a hero! Toward a validation of the healthy and resilient organization (HERO) model. Group \& Organization Management, 37, 785-822. http://dx.doi.org/10.1177/1059601112470405

[17] Demerouti, E., Bakker, A.B., Nachreiner, F. and Schaufeli, W.B. (2001) The job demands-resources model of burnout. Journal of Applied Psychology, 86, 499-512. http://dx.doi.org/10.1037/0021-9010.86.3.499

[18] Leiter, M.P., Harvie, P. and Frizzell, C. (1998) The correspondence of patient satisfaction and nurse burnout. Social Science and Medicine, 47, 1611-1617. http://dx.doi.org/10.1016/S0277-9536(98)00207-X

[19] Garman, A.N., Corrigan, P.W. and Morris, S. (2002) Staff burnout and patient satisfaction: Evidence of relationships at care unit level. Journal of Occupational Health Psychology, 7, 235-241. http://dx.doi.org/10.1037/1076-8998.7.3.235

[20] Vahey, D.C., Aiken, L.H., Sloane, D.M., Clarke, R.N. and Vargas, D. (2004) Nurse burnout and patient satisfaction. Medical Care, 42, II57-II66.

[21] Argentero, P., Dell'Olivo, B. and Ferretti, M.S. (2008) Staff burnout and patient satisfaction with the quality of dialysis care. American Journal of Kidney Diseases, 51, 80-92. http://dx.doi.org/10.1053/j.ajkd.2007.09.011

[22] Weng, H., Hung, C., Liu, Y., Cheng, Y., Yen, C., Chang, C. and Huang, C. (2011) Association between emotional intelligence and doctor burnout, job satisfaction and patient satisfaction. Medical Education, 45, 835-842. http://dx.doi.org/10.1111/j.1365-2923.2011.03985.x

[23] Teng, C., Hsiao, F. and Chou, T. (2010) Nurse perceived time pressure and patient perceived care quality. Journal of Nursing Management, 18, 275-284. http://dx.doi.org/10.1111/j.1365-2834.2010.01073.x

[24] Karasek, R. (1985) Job content instrument questionnaire and user's guide, Version 1.1. Department of Industrial and Systems Engineering, University of Southern California, Los Angeles.

[25] Cho, S.I., Lim, S.H., Um, K.D., Han, I.I., Yoon, G.W., Paek, D.M., et al. (2005) A pilot study for JCQ 2.0 among 
Korean subway workers. 2nd ICOH International Conference on Psychosocial Factors at Work, Okayama, 23-26 August 2005.

[26] Dormann, C. and Zapf, D. (2004) Customer-related social stressors and burnout. Journal of Occupational Health Psychology, 9, 61-82.

http://dx.doi.org/10.1037/1076-8998.9.1.61

[27] Maslach, C. and Jackson, S.E. (1986) Maslach burnout inventory. 2nd Edition, Consulting Psychologists Press, Palo Alto.

[28] Sirigatti, S. and Stefanile, C. (1993) Adattamento italiano del MBI-Maslach burnout inventory. Organizzazioni Speciali, Firenze. http://dx.doi.org/10.1080/02678370500297720

[29] Kristensen, T., Borritz, M., Villadsen, E. and Christensen, K.B. (2005) The Copenhagen burnout inventory: A new tool for the assessment of burnout. Work \& Stress, 19,
192-207. http://dx.doi.org/10.1080/02678370500297720

[30] Franci, A. and Corsi, M. (1999) Verso l'assistenza domiciliare integrata, una proposta di metodo per valutare. Edizioni Summa, Padova.

[31] Maes, S. (2013) Quality of life of patients and health care professionals. The European Health Psychologist, 15, 48-52.

[32] Converso, D. and Viotti, S. (2012) Benessere, qualità della vita organizzativa e qualità dell'assistenza erogata. In: Converso, D., Ed., Benessere Organizzativo in Sanità, Espress Edizioni, Torino, 10-17.

[33] Capuzzo, M., Landi, F., Bassani, A. Grassi L., Volta C.A. and Alvisi R. (2005) Emotional and interpersonal factors are more important for patient satisfaction with anesthesia. Acta Aneesthesiologica Scandinavica, 45, 735-742. http://dx.doi.org/10.1111/j.1399-6576.2005.00738.x 